\title{
Survival of HIV Infected Children Born to Mothers Enrolled in a PMTCT Program in a Resource Poor Setting*
}

\author{
F. Z. Gumbo" ${ }^{1 \#, ~ G . ~ Q . ~ K a n d a w a s v i k a ~}{ }^{1}$, E. N. Kurewa ${ }^{2}$, K. Duri ${ }^{3}$, P. Chandiwana ${ }^{4}$, \\ M. P. Mapingure ${ }^{4}$, M. Z. Chirenje ${ }^{5}$, B. Stray-Pedersen ${ }^{2}$
}

\begin{abstract}
${ }^{1}$ Department of Pediatrics and Child Health, University of Zimbabwe, Harare, Zimbabwe; ${ }^{2}$ Division of Obstetrics and Gynecology, Faculty of Medicine, University of Oslo and Rikshospitalet, Oslo, Norway; ${ }^{3}$ Department of Immunology, University of Zimbabwe, Harare, Zimbabwe; ${ }^{4}$ Letten Foundation Research Centre, Harare, Zimbabwe; ${ }^{5}$ Department of Obstetrics and Gynecology, University of Zimbabwe, Harare, Zimbabwe.
\end{abstract}

Email: " zvanyadz@mweb.co.zw

Received March 26 ${ }^{\text {th }}, 2013$; revised April 25 ${ }^{\text {th }}, 2013$; accepted May $2^{\text {nd }}, 2013$

Copyright (C) 2013 F. Z. Gumbo et al. This is an open access article distributed under the Creative Commons Attribution License, which permits unrestricted use, distribution, and reproduction in any medium, provided the original work is properly cited.

\begin{abstract}
Background: Pediatric HIV is a leading cause of morbidity and mortality worldwide. The substantial expansion in PMTCT has generated information on rates of transmission and associated factors, but there are limited studies on disease progression and mortality in vertically infected children, especially from resource poor settings. Methods: A birth cohort study was initiated in 2002 to focus on the role of a single dose of nevirapine in HIV transmission before Highly Active Antiretroviral Therapy (HAART) was readily available. The enrolment of women and subsequent follow up of the children occurred at 3 peri urban clinics around Harare. Findings: 479 women were HIV infected. From these, 93 $(19 \%)$ children became HIV infected, $182(38.0 \%)$ uninfected and $204(43 \%)$ lost to follow up before HIV diagnosis. Of the HIV infected children, 40 (43\%) died before the fifth birthday, $26(28 \%)$ were lost to follow up and $27(29 \%)$ were alive five years after maternal enrolment prior to availability of cART. Conclusion: In this setting, there was unacceptable high mortality from HIV infected children and loss to follow up prior to availability of HAART. A small proportion of HIV vertically infected children is surviving in resource poor settings without antiretroviral therapy.
\end{abstract}

Keywords: HIV Infected Children Outcome; Mortality; Loss to Follow Up

\section{Introduction}

Highly prevalent mother to child HIV transmission has given rise to pediatric AIDS mortality, especially in countries where resources are few. It has been difficult to follow up HIV exposed infants, so that timely diagnosis of HIV infection can be made which results in appropriate treatment, care and support. Several studies have reported short term survival of HIV exposed children from

\footnotetext{
"Sources of funding: Letten Foundation Norway. Partially presented as an e-poster at the First Global congress for consensus in Pediatrics and Child health. 17-20 February 2011, Marriott Rive Gauche hotel, Paris, France.

Author's contributions: FZG collected data and drafted the manuscript, GQK, NEK, PC and KD assisted in data collection, CZM supervised data collection, MPM participated in data analysis and interpretation of results, BSP designed the study. All authors revised and approved the draft manuscript.

${ }^{\#}$ Corresponding author.
}

vertical transmission [1-4]. The substantial interest in PMTCT has generated information on short term survival of vertically infected children both in the pre Highly Active Antiretroviral Therapy (HAART) and post HAART era particularly in developed countries [3-6]. On the other hand, there is very little information on long-term survival of these children in resource poor settings where follow up is a challenge. Child mortality is independently associated with maternal HIV status and maternal death, with pediatric infection resulting in approximately a four fold increase in mortality by the age of two years compare to HIV unexposed infants [7]. To determine the proportion of children whose mothers had enrolled in the Better Health for the African Mother and Child cohort and were surviving at 5 years of age, a cross sectional study of HIV infected children was carried out between 2007 and 2008 prior to universal access of antiretroviral drugs in Zimbabwe. 


\section{Methods}

The study was conducted at three primary maternal child health clinics in peri-urban areas around Harare (namely Epworth, Seke North and St Mary's) in Zimbabwe.

The initial study was a cohort study of HIV infected pregnant women who had been enrolled in a PMTCT program between 2002 and 2003. The follow up of mothers and children occurred up until 15 months of post natal age and ceased. We describe cross-sectional characteristics of HIV exposed children after a five year follow up visit.

The pregnant women were enrolled into the cohort study from 36 weeks of gestation, after obtaining informed consent. The aim of the initial study was to explore the role of sexually transmitted infections in pregnancy outcome. Pre and post HIV test counseling were offered as part of the national PMTCT program. Baseline characteristics collected included sociodemographic information, medical history of sexually transmitted infections, gynecological examination findings and specimen collection for full blood counts, serology for herpes simplex type 2 and syphilis, and high vaginal swabs for culture. All HIV infected women were given a single dose of nevirapine at delivery; their infants received a single dose of nevirapine, according to the national guidelines at that time (HIVNET 012) [8]. The infants were then followed up at 6weeks, 4 months, 9 months and 15 months and HIV status determined by HIV DNA PCR (Roche Diagnostics, Indianapolis, USA) if the children were aged less than 15 months, and rapid HIV antibody tests, Determine (Abbott Diagnostics, Illinois, USA) and Oraquick (abbott before 15 months and antibody tests at 15 months. The proportion of HIV infected infants has been reported [9].

At the 5 year follow up visit, HIV infected women who had been enrolled in the BHMAC study were identified from registers and traced to their homes where in- formation on survival of their children was collected. HIV infected children were also identified from pediatric follow up clinics and blood was collected for CD4 counts.

\subsection{Data Handling and Analysis}

Information was collected with the data collecting tool and results were analyzed using Stata version 10.0 (College Station, Texas, USA). Cox proportional hazard ratios were used to determine baseline factors associated with child mortality. Characteristics of survivors were also described using percentages for categorical variables and mean (standard deviations) for continuous variables.

\subsection{Ethics}

The mothers or legal guardians signed an informed consent. The study was approved by the Medical Research Council of Zimbabwe (MRCZ) and the Norwegian ethical review committee.

\section{Results}

Figure 1 shows the follow up of HIV infected infants born from the recruited mothers, 27 out of 93 (29\%) HIV infected children survived. There were no significant differences in maternal baseline characteristics, notably haemoglobin $\mathrm{p}=0.563$, total lymphocyte count $\mathrm{p}=0.557$, age $p=0.067$ and disclosure of HIV status to partner $p=$ 0.733 between the 204 children who were lost before HIV diagnosis and those tested for HIV. Table 1 shows unadjusted hazard ratios for predictors of child mortality. Breast feeding at 4 months was protective of death $p=$ 0.002 , which is reflected at 6 weeks and 9 months but not statistically significant. We were able to postulate causes of mortality by verbal autopsy in 27 patients. Of these, $13(48 \%)$ died from pneumonia, $13(48 \%)$ from diarrhea and $1(4 \%)$ from asthma.

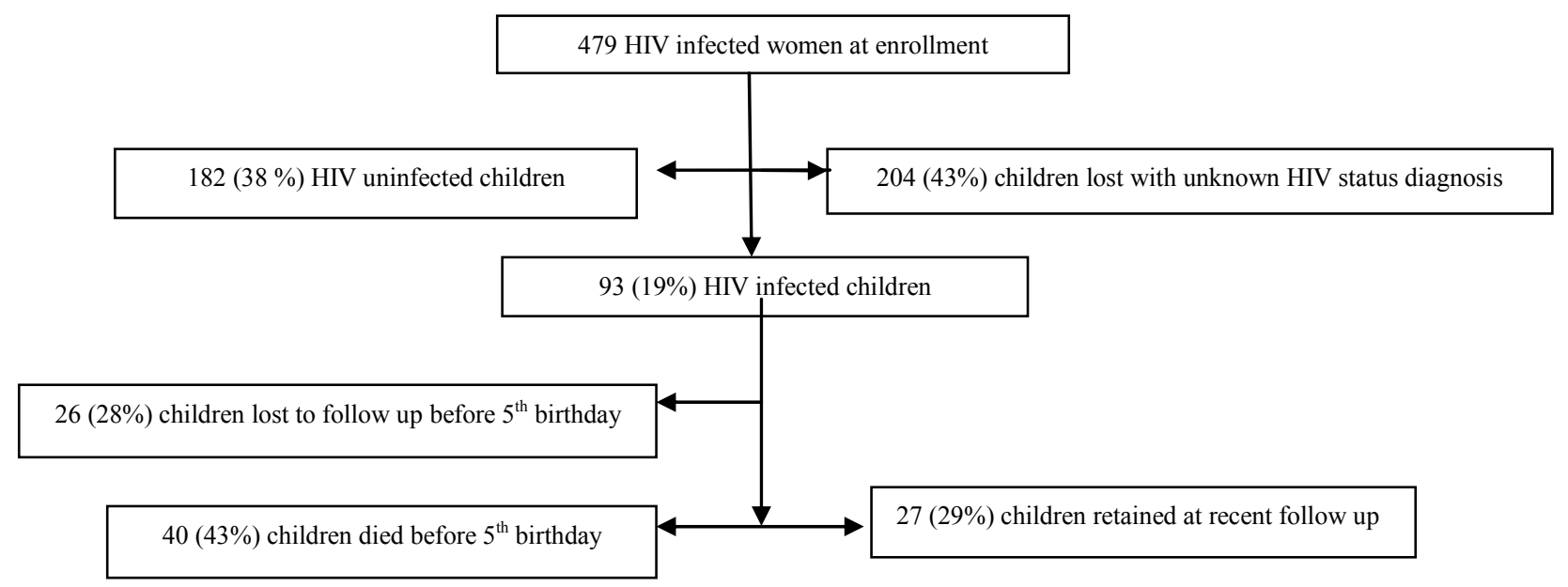

Figure 1. Follow up and retention of HIV infected infants in the cohort. 
Table 1. Unadjusted hazard ratio for predictors of child mortality.

\begin{tabular}{|c|c|c|}
\hline Predictor & Hazard ratio ( $95 \%$ confidence interval) & $p$ value (cox regression) \\
\hline \multicolumn{3}{|l|}{$\operatorname{Sex} N=85$} \\
\hline \multicolumn{3}{|l|}{ Male } \\
\hline Female & $0.81(0.41-1.61)$ & 0.549 \\
\hline \multicolumn{3}{|l|}{ Delivery weight (g) $N=80$} \\
\hline \multicolumn{3}{|l|}{$<2500(\%)$} \\
\hline$\geq 2500 \mathrm{n}(\%)$ & $0.88(0.31-2.50)$ & 0.816 \\
\hline Head circumference at birth $(\mathrm{cm})$ & $0.90(0.75-1.07)$ & 0.228 \\
\hline Length at birth $(\mathrm{cm})$ & $0.99(0.89-1.09)$ & 0.796 \\
\hline \multicolumn{3}{|l|}{ Breast feeding at 6 weeks } \\
\hline \multicolumn{3}{|l|}{ No } \\
\hline Yes & $0.56(0.17-1.83)$ & 0.336 \\
\hline \multicolumn{3}{|l|}{ Breast feeding at 4 months } \\
\hline \multicolumn{3}{|l|}{ No } \\
\hline Yes & $0.25(0.11-0.60)$ & 0.002 \\
\hline \multicolumn{3}{|l|}{ Breast feeding at 9 months } \\
\hline \multicolumn{3}{|l|}{ No } \\
\hline Yes & $0.51(0.16-1.58)$ & 0.241 \\
\hline \multicolumn{3}{|l|}{ Baby ever breastfed $\mathrm{N}=86$} \\
\hline \multicolumn{3}{|l|}{ No } \\
\hline Yes & $0.82(0.29-2.32)$ & 0.712 \\
\hline \multicolumn{3}{|l|}{ Mother died $\mathrm{N}=93$} \\
\hline \multicolumn{3}{|l|}{ No } \\
\hline Yes & $2.54(0.78-8.26)$ & 0.121 \\
\hline
\end{tabular}

From 27 Children who survived (Figure 1), 23 children were not on antiretroviral therapy at the 5 year follow up visit. Table 2 shows children's characteristics at the 5 year follow up visit. Six out of 23 children (26\%) were eligible for antiretroviral therapy (cART) but not yet on cART.

\section{Discussion}

The results depict an unacceptably high mortality of HIV infected children in the cohort and loss to follow up rate before and after HIV diagnosis. About $43 \%$ died before the $5^{\text {th }}$ birthday which supports the urgent need of the prevention of mother to child transmission of HIV and the early diagnosis and treatment of HIV infection in children in Zimbabwe. As expected, mortality has been shown to be higher among HIV infected children compared to HIV-exposed but uninfected children [10]. Several studies have reported early mortality in HIV infected infants but few on long term outcome in Africa [11,12]. Kuhn et al. reported $77.1 \%$ mortality by 24 months in Zambia among HIV infected children [13].

Avoidance of breastfeeding eliminates the risk of HIV transmission through breast milk but is detrimental to child survival. Increased infant morbidity and mortality have been reported in several sub-Saharan African countries [14-17] in non-breastfed infants. In our study, the
Table 2. Children's characteristics at 5 year follow up visit.

\begin{tabular}{lc}
\hline \multicolumn{1}{c}{$\begin{array}{c}\text { Children's characteristics at } 5 \text { years } \\
\text { follow up visit not receiving ART. }\end{array}$} & $\mathrm{N}=23$ \\
\hline Sex & \\
Male (\%) & $13(57 \%)$ \\
Female & $10(43 \%)$ \\
Age in months (SD) & $56(11)$ \\
Mean CD4 counts (SD) & $1044(741)$ \\
Mean CD4 percentages (N $=22)(\mathrm{SD})$ & $24(13)$ \\
Number eligible for ART $(<350 /<15 \%)$ & $6(26 \%)$ \\
\hline
\end{tabular}

protective association of breast feeding was evident at 4 months but not statistically significant at 6 weeks and 9 months. This could be explained by the small numbers of HIV infected children. Although not statistically significant, the hazards ratio for children whose mothers died was more than twice. Studies from Africa have shown that maternal death is associated with child mortality. Mothers who have advanced HIV disease are unlikely to care for their children adequately and/or may carry infectious pathogens which are harmful to their children [18-20]. Marinda et al. identified low birth weight and male sex as risk factors of mortality in HIV exposed children [21]. Our results show a similar tendency. 
Approximately one-third of HIV-infected children in sub-Saharan Africa who have no access to antiretroviral therapy are estimated to die by 1 year of age, and approximately one-half are estimated to die by 2 years of age [22]. However, these estimates are based on a limited number of observational and prospective studies [7].

The national program in Zimbabwe introduced HAART in 2008. It was during this time when the health delivery system faced a lot of socioeconomic challenges, so accessibility of the national program was somewhat limited. The majority of the children demised before HAART was the public domain although a few in the private sector could access the drugs. PMTCT coverage increased from $22 \%$ in 2007 to $42.6 \%$ in 2008 in Zimbabwe [23,24]. In $2009,56 \%$ of HIV-positive pregnant women received antiretroviral (ARVs) for PMTCT and only $35 \%$ of HIV-exposed infants received prophylactic ARVs for PMTCT [25].

Unfortunately in this study there was a significant loss to follow up before and after diagnosis of HIV infection of children who participated in the study. We were unable to measure HIV viral loads of remaining HIV infected children. In conclusion, in this resource poor setting, there was a high mortality of HIV exposed children pre and post diagnosis.

\section{Acknowledgements}

We gratefully acknowledge the women and children who participated in this study. Special mention goes to the Better Health for the African Mother and Child Research Team and to The Letten Foundation including Professor Letten herself for funding.

\section{REFERENCES}

[1] D. Chilongozi, L. Wang, L. Brown, T. Taha, M. Valentine, E. Emel, M. Sinkala, G. Kafulafula, R. A. Noor, J. S. Read, E. R. Brown, R. L. Goldenberg and I. Hoffman, "Morbidity and Mortality among a Cohort of Human Immunodeficiency Virus Type 1-Infected and Uninfected Pregnant Women and Their Infants from Malawi, Zambia and Tanzania," Pediatric Infectious Disease Journal, Vol. 27, No. 9, 2008, pp. 808-814.

[2] P. Lumbiganon, A. Kariminia, L. Aurpibul, R. Hansudewechakul, T. Puthanakit, N. Kurniati, N. Kumarasamy, K. Chokephaibulkit, N. K. N. Yusoff, S. Vonthanak, F. S. Moy, K. A. M. Razali, R. Nallusamy and A. H. Sohn, "Survival of HIV-Infected Children: A Cohort Study from the Asia-Pacific Region," Journal of Acquired Immune Deficiency Syndromes, Vol. 56, No. 4, 2011, pp. 365-371.

[3] C. Diaz, C. Hanson, E. R. Cooper, J. S. Read, J. Watson, H. A. Mendez, J. Pitt, K. Rich, V. Smeriglio and J. F. Lew, "Disease Progression in a Cohort of Infants with Vertically Acquired HIV Infection Observed from Birth: The Women and Infants Transmission Study (WITS)," Journal of Acquired Immune Deficiency Syndromes and $\mathrm{Hu}$ - man Retrovirology, Vol. 18, No. 3, 1998, pp. 221-228. doi:10.1097/00042560-199807010-00004

[4] P. A. Tovo, M. de Martino, C. Gabiano, N. Cappello, R. D'Elia, A. Loy, A. Plebani, G. V. Zuccotti, P. Dallacasa and G. Ferraris, "Prognostic Factors and Survival in Children with Perinatal HIV-1 Infection: The Italian Register for HIV Infections in Children," Lancet, Vol. 339, No. 8804, 1992, pp. 1249-1253. doi:10.1016/0140-6736(92)91592-V

[5] D. Dunn, "Short-Term Risk of Disease Progression in HIV-1-Infected Children Receiving No Antiretroviral Therapy or Zidovudine Monotherapy: A Meta-Analysis," Lancet, Vol. 362, No. 9396, 2003, pp. 1605-1611. doi:10.1016/S0140-6736(03)14793-9

[6] A. Violari, M. F. Cotton, D. M. Gibb, A. G. Babiker, J. Steyn, S. A. Madhi, P. Jean-Philippe and J. A. McIntyre (CHER Study Team), "Early Antiretroviral Therapy and Mortality among HIV-Infected Infants," New England Journal of Medicine, Vol. 359, No. 2, 2008, pp. 2233-2244.

[7] K. Little, C. Thorne, C. Luo, M. Bunders, N. Ngongo, P. McDermott and M. L. Newell, "Disease Progression in Children with Vertically-Acquired HIV Infection in SubSaharan Africa: Reviewing the Need for HIV Treatment," Current HIV Research, Vol. 5, No. 2, 2007, pp. 139-153.

[8] L. A. Guay, P. Musoke, T. Fleming, D. Bagenda, M. Allen, C. Nakabiito, J. Sherman, P. Bakaki, C. Ducar, M. Deseyve, L. Emel, M. Mirochnick, M. G. Fowler, L. Mofenson, P. Miotti, K. Dransfield, D. Bray, F. Mmiro and J. B. Jackson, "Intrapartum and Neonatal Single Dose Nevirapine Compared with Zidovudine for Prevention of Mother to Child Transmission of HIV-1 in Kampala, Uganda, HIVNET 012 Randomized Trial," Lancet, Vol. 354, No. 9181, 1999, pp. 795-802.

[9] F. Z. Gumbo, E. N. Kurewa, G. Q. Kandawasvika, K. Duri, M. P. Mapingure, M. W. Munjoma, I. E. Pazvakavambwa, S. Rusakaniko, M. Z. Chirenje and B. StrayPedersen, "Rising Mother to Child HIV Transmission in a Resource Limited Breast Feeding Population," Tropical Doctor, Vol. 40, No. 2, 2010, pp. 70-73.

doi:10.1258/td.2009.090167

[10] F. Dabis and E. R. Ekpini, "HIV-1/AIDS and Maternal and Child Health in Africa," Lancet, Vol. 359, No. 9323 , 2002, pp. 2097-2104.

doi:10.1016/S0140-6736(02)08909-2

[11] L. Zijenah, M. T. Mbizvo, J. Kasule, K. Nathoo, M. Munjoma, et al., "Mortality in the First Two Years among Infants Born to HIV-Infected Women in Harare, Zimbabwe," Journal of Infectious Diseases, Vol. 178, No. 1, 1998, pp. 109-113. doi:10.1086/515604

[12] L. S. Zijenah, L. H. Moulton, P. Illiff, K. Nathoo, M. Munjoma, et al., "Timing of Mother to Child Transmission of HIV 1 and Infant Mortality in the First 6 Months of Life in Harare, Zimbabwe," AIDS, Vol. 18, No. 2, 2004, pp. 273-280.

[13] L. Kuhn, G. M. Aldrovandi, M. Sinkala, C. Kankasa, K. Semrau, et al., "Effects of Early, Abrupt Weaning on HIVFree Survival of Children in Zambia," New England Journal of Medicine, Vol. 359, No. 2, 2008, pp. 130-141.

[14] J. Vyankandondera, S. Luchters, E. Hassink, et al., "Sim- 
ba-Stopping Infection from Mother to Child via Breastfeeding in Africa," In: Program and Abstracts of the 3rd International AIDS Society Conference on HIV Pathogenesis, Paris, 2003, Abstract LB07.

[15] Kesho Bora Study Group, "Triple-Antiretroviral Prophylaxis during Pregnancy and Breastfeeding Compared to Short-ARV Prophylaxis to Prevent Mother-to-Child Transmission of HIV-1: The Kesho Bora Randomized Controlled Clinical Trial in Five Sites in Burkina Faso, Kenya and South Africa," In: Program and abstracts of the 5th International AIDS Society Conference on HIV Pathogenesis, Treatment, and Prevention, Capetown, 2009, Abstract LBPE C01.

[16] D. Jamieson, C. S. Chasela, M. G. Hudgens, C. C. King, A. P. Kourtis, D. Kayira, et al., "Maternal and Infant Antiretroviral Regimens to Prevent Postnatal HIV-1 Transmission: 48-Week Follow-Up of the BAN Randomised Controlled Trial," Lancet, Vol. 379, No. 9835, 2012, pp. 2449-2458. doi:10.1016/S0140-6736(12)60321-3

[17] H. M. Coovadia, E. R. Brown, M. G. Fowler, T. Chipato, D. Moodley, K. Manji, et al., "Efficacy and Safety of an Extended Nevirapine Regimen in Infant Children of Breastfeeding Mothers with HIV-1 Infection for Prevention of Postnatal HIV-1 Transmission (HPTN 046): A Randomized, Double-Blind, Placebo-Controlled Trial," Lancet, Vol. 379, No. 9812, 2011, pp. 221-228.

[18] M. Newell, H. Brahmbatt and P. Ghs, "Child Mortality and HIV Infection on Africa: A Review," AIDS, Vol. 18,
Suppl. 2, 2004, pp. s27-s34.

[19] M. Newell, H. Coovadia, M. Cortina-Borja, N. Rollins, P. Gaillard, et al., "Mortality of Infected and Uninfected Infants Born to HIV-Infected Mothers: A Pooled Analysis," Lancet, Vol. 364, No. 9441, 2004, pp. 1236-1243.

[20] R. Becquet, M. Marston, F. Dabis, L. H. Moulton, G. Gray, et al., "Children Who Acquire HIV Infection Perinatally Are at Higher Risk of Early Death than Those Acquiring HIV through Breastmilk: A Meta-Analysis," PLoS One, Vol. 7, No. 2, 2012, p. e28510.

[21] E. Marinda, J. H. Humphrey, P. J. Iliff, K. Mutasa, K. J. Nathoo, et al., "Child Mortality According to Maternal and Infant HIV Status in Zimbabwe," Pediatric Infectious Disease Journal, Vol. 26, No. 6, 2007, pp. 519-526. doi:10.1097/01.inf.0000264527.69954.4c

[22] UNAIDS, “AIDS Epidemic Update," World Health Organization, Geneva, 2007.

[23] "Module 9: More Efficacious ARV Prophylaxis of Mother to Child Transmission (PMTCT)," MOHCW, 2008.

[24] "PMTCT Programme 2008 Annual Report," AIDS \& TB Unit, MOHCW, 2008.

[25] Towards Universal Access: Scaling up Priority HIV/ AIDS Interventions in the Health Sector," Progress Report, WHO, UNAIDS, UNICEF, 2009. data.unaids.org/pub/Report/2009/20090930_tuapr_2009_ en.pdf 